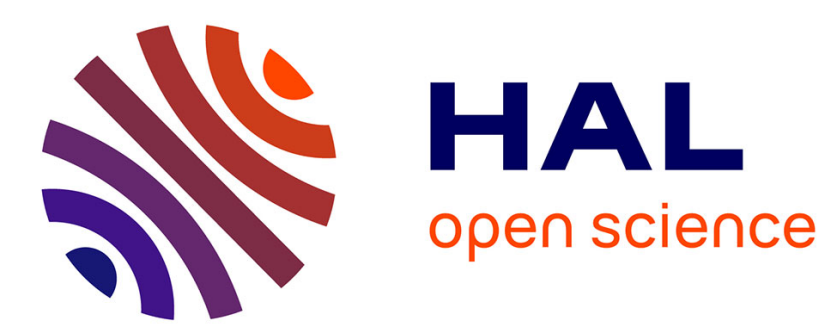

\title{
Vacancies and Dominant Electrically Active Defects in Bulk Semi-Insulating GaAs
}

\author{
M. Brozel, C. Corbel
}

\section{To cite this version:}

M. Brozel, C. Corbel. Vacancies and Dominant Electrically Active Defects in Bulk Semi-Insulating GaAs. Journal de Physique IV Proceedings, 1995, 05 (C1), pp.C1-63-C1-72. 10.1051/jp4:1995107. jpa-00253543

\section{HAL Id: jpa-00253543 https://hal.science/jpa-00253543}

Submitted on 1 Jan 1995

HAL is a multi-disciplinary open access archive for the deposit and dissemination of scientific research documents, whether they are published or not. The documents may come from teaching and research institutions in France or abroad, or from public or private research centers.
L'archive ouverte pluridisciplinaire HAL, est destinée au dépôt et à la diffusion de documents scientifiques de niveau recherche, publiés ou non, émanant des établissements d'enseignement et de recherche français ou étrangers, des laboratoires publics ou privés. 


\title{
Vacancies and Dominant Electrically Active Defects in Bulk Semi-Insulating GaAs
}

M.R. Brozel and C. Corbel*

Centre for Electronic Materials, UMIST, P.O. Box 88, Manchester, M60 IQD, U.K.

* INSTN, Gif-sur-Yvette, Saclay, France

\begin{abstract}
Positron Annihilation techniques have been used to investigate two important defects that occur naturally in semi-insulating (SI) Gallium arsenide. The growth and assessment of SI $\mathrm{GaAs}$ and the application of PA to defect analysis of this important material are reported.
\end{abstract}

\section{INTRODUCTION}

The increasing use of GaAs for High Speed Digital and Monolithic Microwave Integrated Circuits is due mostly to the ready availability of semi-insulating (SI) GaAs. The SI behaviour of GaAs substrates is of primary importance because components fabricated on their surfaces experience virtually no parasitic shunt capacitances to the substrate. Other advantages cited for GaAs in high speed devices are based on the low effective mass and high mobility of conduction electrons in GaAs. In reality, these are of lesser importance because under the high electric fields under which most GaAs devices work electrons are converted to higher effective mass particles via the transferred electron effect and their saturated velocities are no greater than what can be obtained in silicon under the same circumstances [1].

It is possible to make SI GaAs by simply growing undoped material from the melt in circumstances where the predominant impurities are acceptors. Most SI GaAs is produced by the Liquid Encapsulated Czochralski (LEC) method where the crystal is pulled from a melt of Ga and As through a liquid encapsulant; the latter acting as a barrier to the evaporation of arsenic vapour from the melt. LEC GaAs is notorious for containing a large number of dislocations, most of which are polygonised into dislocation cell walls of linear dimension around $200 \mu \mathrm{m}$. It is accepted that the majority of dislocations are introduced soon after growth and are produced by the cooling process which is by radiation and convection of heat from the crystal surface into the ambient. The former is uncontrolled as the radiation takes place into a cool chamber; the latter is controllable to an extent by varying the pressure of the ambient gas within the puller. Both these mechanisms result in a large radial temperature gradient within the crystal. Unfortunately, GaAs is a poor thermal conductor with a low critically resolved sheer stress (CRSS) at high temperatures. The contraction of the outside of the crystal as it cools onto the rest of the crystal produces considerable plastic deformation via slip, and it is the production of slip dislocations that results in the very high dislocation densities of $10^{4}$ to $10^{5} \mathrm{~cm}^{-2}$ which are typically observed and, indeed, predicted by theory [2]. The polygonisation of the dislocations must take place at temperatures close to the melting point as this requires, in addition to glide, considerable dislocation climb.

Newer methods for growing this material include the Vertical Gradient Freeze (VGF) and Vertical Bridgman (VB) techniques where the melt is solidified within a mould and where it is possible to control 
the heat flow and the growth more accurately. Because of the reduced thermal stresses the dislocation density is markedly lower, often around $10^{2}$ to $10^{3} \mathrm{~cm}^{-2}$. However, even in these cases, dislocations are found to have polygonised into cells whose linear dimensions can exceed several millimetres [3]. The relevance of dislocations to point defects is that the distributions of the latter are controlled by the dislocations and it is this aspect that results in the non-uniformities that have been the bane of GaAs users for many years.

A reflection X-ray topograph showing typical dislocation arrays in a commercial GaAs substrate is shown in figure 1. The dislocation arrays form cells which dominate towards the crystal axis and lineage features which have been shown to be low angle tilt grain boundaries. Additional slip is also seen in figure 1, apparently as a result of plastic deformation at rather lower temperatures where dislocation climb and subsequent polygonisation is not possible.

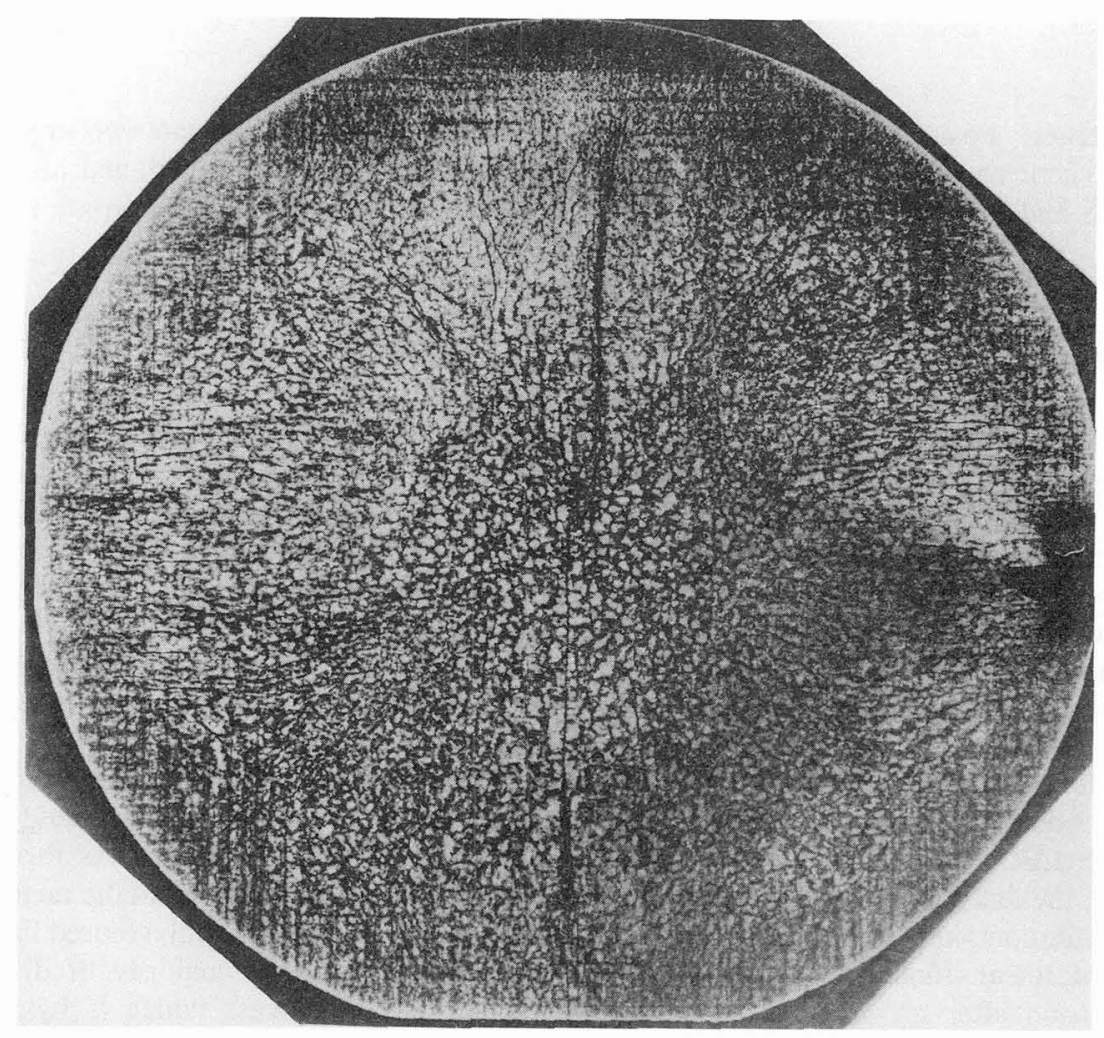

Figure 1. Reflection X-ray topograph of a commercial GaAs substrate of $50 \mathrm{~mm}$ diameter revealing dislocation arrays. Cell structure is seen towards the centre of the wafer whilst the linear features towards the periphery are lineage (see text). The fine features close to the periphery are due to slip.

In all of these techniques, it is found that the predominant impurity is carbon. In the LEC technique, carbon is introduced in two ways; firstly, it is thought to be a contaminant in the Ga and As feedstock and is introduced into the melt directly. Secondly, it has been proved that carbon is introduced into the melt via the gas phase, apparently through the liquid encapsulant after a reaction between various oxygen containing components in the high pressure ambient gas and the heater assembly surrounding the crucible. It has been demonstrated that the carrier gas is carbon monoxide and various workers have demonstrated the controlled introduction of carbon by varying the $\mathrm{CO}$ vapour pressure [4]. The melt 
is held in a crucible of pyrolytic boron nitride (pBN) which is believed to be inert. Similar crucibles are used in the VGF and VB techniques and the introduction of carbon into the GaAs is probably due to direct doping or introduced via the $\mathrm{Ga}$ and As elements.

SI behaviour results from the compensation of (carbon) acceptor impurities by a native deep donor known as EL2 [5]. EL2 exists in a neutral state EL2 ${ }^{\circ}$ and a singly positively ionised state, EL2 ${ }^{+}$. EL2 is the deepest of several native deep donors whose ionisation energies extend from just below the conduction band to EL2 which is very close to mid-bandgap. In SI material, the Fermi energy is controlled by the partial ionisation of EL2 centres and it follows that all donors more shallow than EL2 are fully ionised. The rather fortuitous pinning of the Fermi energy at EL2 in nearly all GaAs grown from the melt results from the wide range of concentrations of shallow donors, shallow acceptors, donors less deep than EL2 and EL2 defects, respectively. Thus, the aggregate concentrations of shallow donors are less than $10^{14}$ $\mathrm{cm}^{-3}$, shallow acceptors, most of which are carbon, from $10^{14}$ to $10^{15} \mathrm{~cm}^{-3}$, EL2 from 1 to $2 \times 10^{16} \mathrm{~cm}^{-}$ 3 and other deep donors less shallow than EL2 in the range of $10^{14} \mathrm{~cm}^{-3}[6]$.

\section{EL2 CENTRES AND DISLOCATIONS}

EL2 centres have optical as well as electrical properties, probably the most important of which is the absorption of sub-bandgap light which occurs in a wide band extending from about $1.5 \mu \mathrm{m}$, increasing nearly monotonically towards the bandedge [7]. It is possible to employ this absorption to map changes in EL2 concentration across substrates [8]. Figure 2 shows a typical EL2 absorption map where it is observed that dark regions, corresponding to higher concentrations of EL2, are distributed in a way similar to that of dislocations. Indeed, an excellent correlation between high concentrations of EL2 and dislocations in virtually all as-grown SI GaAs has been found [9]. This demonstrates the close affinity between point defects and dislocations which, in this case, seems to support the idea of high concentration of point defects diffusing towards dislocations and producing Cotterell atmospheres.

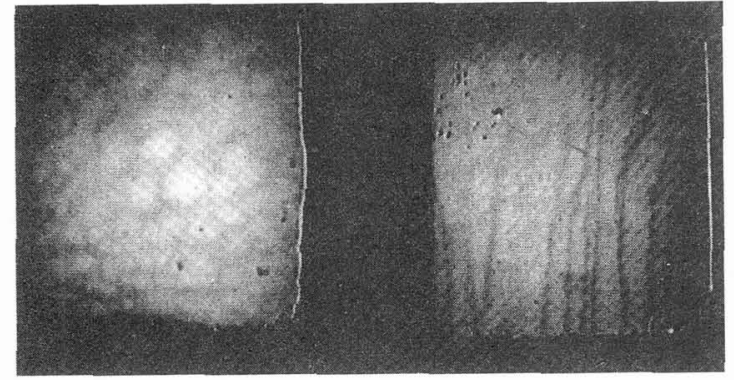

Figure 2. EL2 absorption images taken (a) near the centre and (b) towards the periphery of a $50 \mathrm{~mm}$ diameter wafer showing high EL2 concentrations associated with cell structure and lineage respectively. much as it corresponds to an arsenic richness of two atoms per defect. In other words, one gallium atom is missing and one extra arsenic atom has been introduced into each defect. EL2 defects appear to be stable at temperatures up to $1000^{\circ} \mathrm{C}$. The second attribute of EL2 centres, which was thought to be unique amongst point defects in GaAs, is their rather bizarre behaviour when they are irradiated at low temperatures with sub-bandgap light. Thus, after such an irradiation all electrical and optical properties are rendered inoperative and, for all intents and purposes, the EL2 centres are destroyed. This property is often referred to as photoquenching or bleaching, the EL2 centres being excited to an inert metastaule state, EL2* [11]. Because residual acceptors are no longer compensated, the GaAs becomes p-type. All properties are recovered if the samples are subsequently heated to temperatures above $140 \mathrm{~K}$. 
Although photoquenching of EL2 has been investigated by many workers, the atomic configuration of $\mathrm{EL} 2{ }^{*}$ is not amenable to most experimental techniques because of its inertness. Several theoreticians have postulated that the mode of photoquenching is the jump of the arsenic atom from its Ga lattice site along a (111) ligand towards a nearest neighbour As atom, leaving a $\mathrm{Ga}$ vacancy and producing a metastable defect that is in effect a $\left[\mathrm{As}_{\mathrm{int}} \mathrm{V}_{\mathrm{Ga}}\right.$ ] complex [12]. It has been one of the successes of the Positron Annihilation method that it has been able to detect the vacancy component of this complex [13].

As an example, Figure 3 shows that the $\mathrm{V}_{\mathrm{Ga}}$-like vacancy concentration produced by photoquenching is linearly related to the EL2 concentration [14].

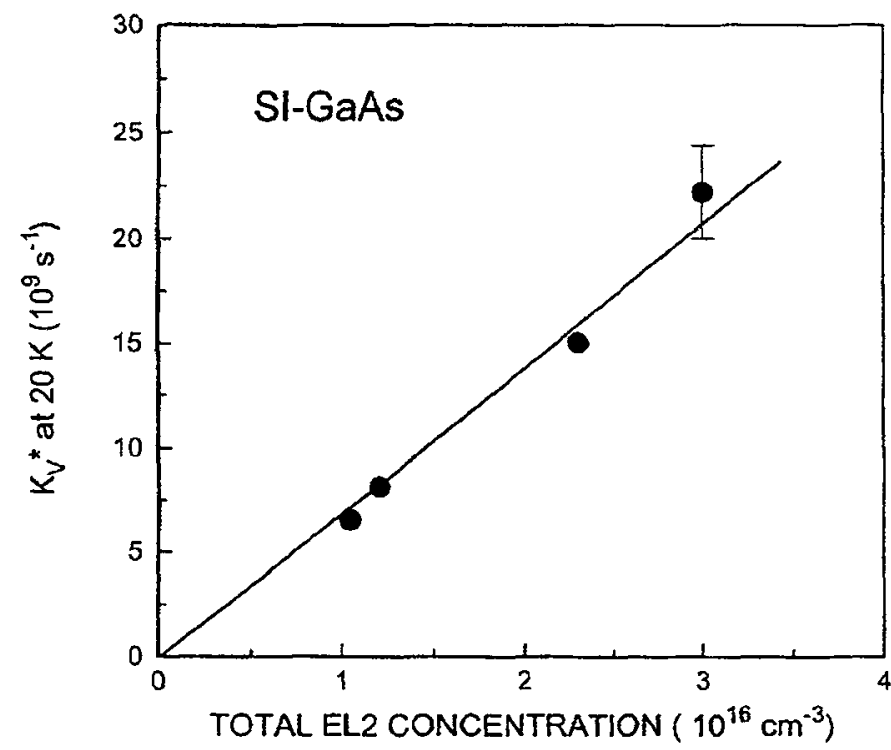

Figure 3. The linear relationship between the trapping rates at $\mathrm{Ga}-$ vacancies after photoquenching of EL2 centres determined by Positron Annihilation and the concentrations of EL2 centres measured previously by optical absorption measurements.
However, one property which appears not to be explained by EL2 centres is that of photo- and cathodo-luminescence (PL and CL, respectively). Luminescence is a well known assessment technique where light emitted from the semiconductor on excitation by above bandgap light (PL) or by irradiation with high energy electrons (CL) is analysed. These techniques require no contacts to be put on the sample and, if they can be performed at room temperature, are non-destructive. At best, luminescence measurements are semi-quantitative and this limits their application. The intensity of $\mathrm{PL}$ or CL is very poor and nonuniform for bulk GaAs demonstrating that most minority carriers that are produced, recombine in a variable, nonradiative manner [15]. Many workers have purported to show that the relative magnitude of the luminescence, especially that arising at near-bandgap energies, correlates with concentrations of

EL2 centres. This is probably incorrect and the interpretation of this PL data in particular has, for many years, been rather confused. PL intensity is actually controlled by another point defect, the "Reverse Contrast" defect [16] and this is amenable to investigation by Positron Annihilation.

At this stage, we note that observations in non-uniformity of luminescence are not simply of academic interest because luminescence intensity in $\mathrm{SI} \mathrm{GaAs} \mathrm{represents} \mathrm{minority} \mathrm{carrier} \mathrm{recombination} \mathrm{time.} \mathrm{In}$ many microwave and digital devices, the predominant device is the MESFET, a device that works by modulating the conductivity of a channel and whose operation is that of a majority carrier device. It would appear therefore that the lifetime of minority carriers is not relevant to its performance. However, there is a major problem which occurs when MESFETs are placed close together in an integrated circuit. This is an interference, known as side-gating, which occurs between adjacent devices, and where rapid switching of one device can cause parasitic switching in an adjacent device - a phenomenon which clearly renders the total circuit inoperable. It is believed that the mechanism for side-gating is the introduction of carriers into the substrate from the switching device that diffuse to a neighbouring device and cause 
modulation of the channel conductivity. Carriers introduced into a semi insulating substrate are minority carriers and they will diffuse further if their lifetime is longer. Because luminescence measures the lifetime, it follows that high luminescence efficiency is indicative of material that will result in bad sidegating, and that non-uniform luminescence efficiency will result in non-uniform side-gating characteristics [17].

It is shown below that the defects that dominate luminescence efficiency are non-uniform even after an ingot anneal, that they can be measured by a quantitative optical absorption technique known as Reverse Contrast absorption imaging and that these defects are amenable to analysis by Positron Annihilation techniques.

\section{REVERSE CONTRAST DEFECTS}

Reverse Contrast (RC) absorption was first observed by Skolnick et al [16] in an investigation of EL2 images. They probed the absorption image of samples cooled below $10 \mathrm{~K}$ as a function of incident light energy and observed, quite unexpectedly, that the absorption image experienced a total change in contrast if the incident light was of photon energy within a few tens of millivolts below $E_{g}$. RC images are shown in figure 4 where the reversal of contrast is apparent. The image disappears if the sample is warmed above $120 \mathrm{~K}$. It is difficult to explain the reasons for these images as it is normally accepted that virtually all impurities and defects aggregate towards dislocations and if any of these were causing absorption, then greater absorption would be found near, and not away from, the dislocations. We note that no electrical activity can be observed that would map according to these images.

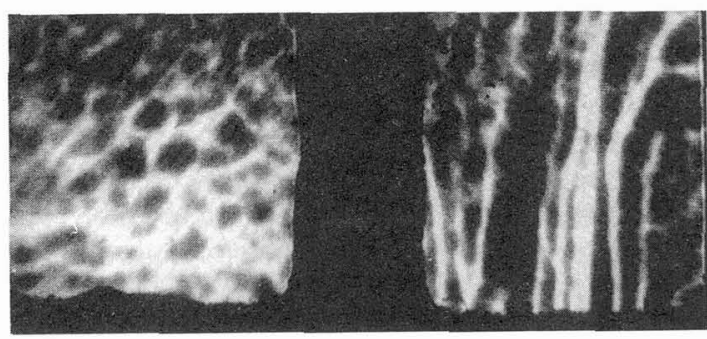

Figure 4. Reverse contrast images taken at a wavelength of $830 \mathrm{~nm}$ and a sample temperature of $80 \mathrm{~K}$ of the same sample as in figure 2 . proved that RC defects cannot be associated with the EL2 defect in either of its two charge states, EL2 ${ }^{\circ}$ and EL. ${ }^{+}[21]$

Surprisingly, RC images are very similar to PL and CL images [22] and this is the relevance of discussing these images. In figure 5 , an $\mathrm{RC}$ absorption image at a sample temperature of $80 \mathrm{~K}$, is compared to a low temperature $(10 \mathrm{~K})$ cathodoluminescence image of the same area of the same sample. The extremely close correspondence between these images is remarkable, especially when the difference in sampling depth is taken into account. Bright regions in the RC image represent little absorption and therefore a low concentration of absorbing defects; similar regions in the CL image represent high luminescence and therefore a lower concentration of parallel recombination paths. We have speculated, therefore, that the $\mathrm{RC}$ image is due to absorption by those defects that act as the dominant non-radiative recombination centre in SI LEC GaAs [23]. Also, it was demonstrated that RC absorption is greater and $\mathrm{PL}$ intensity is lower in samples grown from a Ga-rich melt, allowing us to suggest that the RC defect represents As-deficiency whereas the EL2 defect, known to involve $\mathrm{As}_{\mathrm{Ga}}$, represents As-richness [24]. 

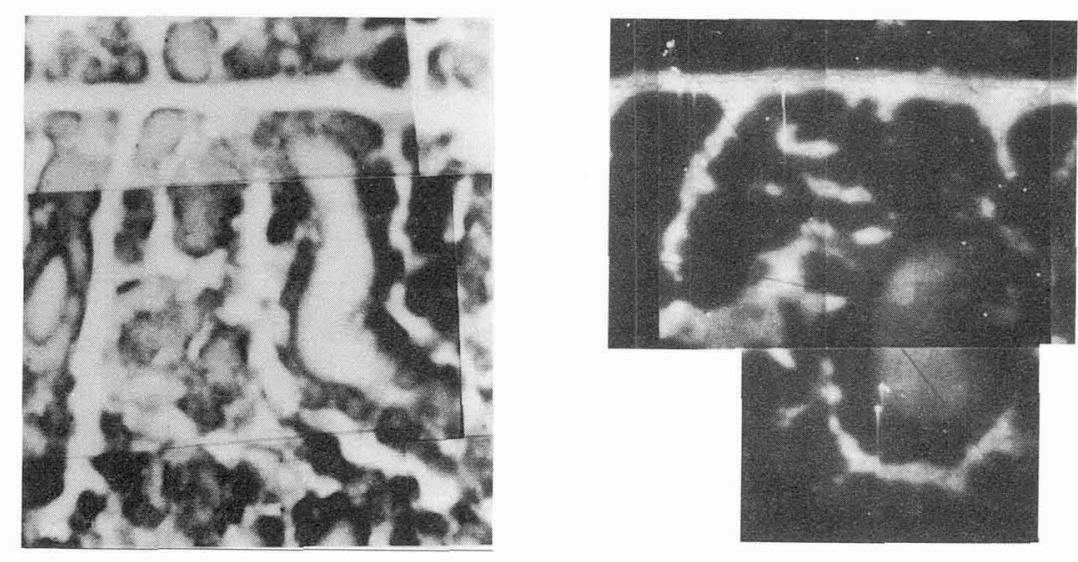

Figure 5. $\mathrm{RC}$ absorption image (left) and a CL image (right) of the same section of sample. The CL image was obtained using the total near-bandedge luminescence.

The photoquenching of the RC absorption image, which renders it brighter, has a parallel in $1 \mathrm{u} \mathrm{m}$ in es ce n c e efficiency; in other words, PL or $\mathrm{CL}$ intensity is increased if $\mathrm{RC}$ defects are previously rendered inoperative by photoquenching. It should be noted that no correlation between PL intensity or the change in PL intensity on photoquenching and EL2 concentration is found [25].

The identification of the deep acceptors that result in the persistent photoconductivity with RC defects was examined in a sample of extremely lightly Te-doped n-type material by a photo-Hall Effect experiment [26]. The depth of the acceptor level in the forbidden gap is not certain, but it should be below the Fermi Energy in ntype GaAs and should, therefore, be ionised and act as a compensating centre. Therefore, we expect that photo-quenching of RC centres should result in a persistent increase in free electron concentration. Figure 6 is a plot of the photo-quenchable carrier concentration (left hand side) and the derived acceptor concentration (right hand side) as functions of the absorption coefficient at $830 \mathrm{~nm}$. A satisfactory linear relationship exists between these quantities from which the optical cross-section of RC defects at a wavelength of $830 \mathrm{~nm}$ is found to be approximately $7 \times 10^{-15} \mathrm{~cm}^{2}$. There is no photo-quenchable change in carrier concentration that relates to EL2 concentrations in any of these samples.

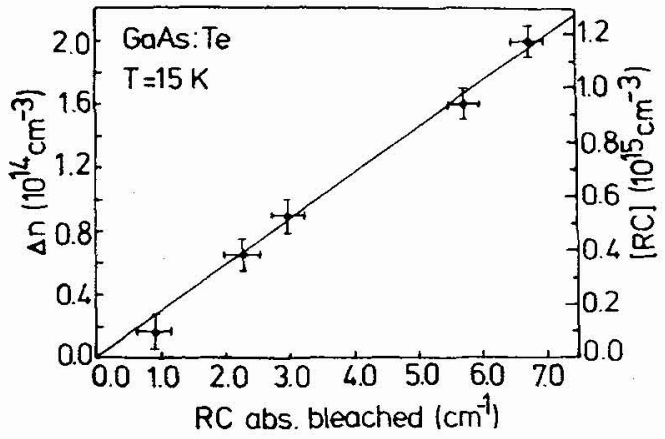

Figure 6. Photoquenchable carrier concentration (left hand scale) and the derived acceptor concentration (right hand scale) plotted against the $\mathrm{RC}$ absorption coefficient.
We conclude that $\mathrm{RC}$ defects are acceptors whose concentrations are of the order of $10^{15} \mathrm{~cm}^{-3}$ in most melt-grown GaAs.

\section{ATOMIC NATURE OF RC DEFECTS}

From comparison with theory, it had been suggested that the RC defect is associated with the As-vacancy [20] because the calculated ionisation energy of the As-vacancy is approximately $E_{g}-50$ $\mathrm{meV}[27,28]$, in close agreement with the $\mathrm{RC}$ absorption threshold energy. 


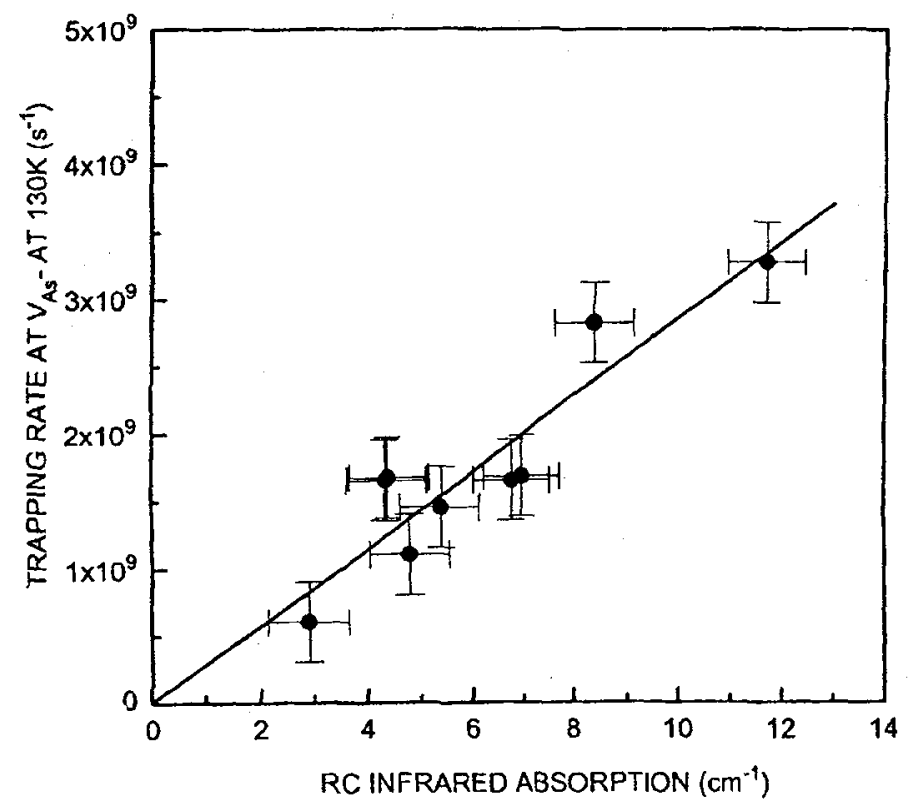

Figure 7. Trapping rate at photo-ionised arsenic vacancies plotted against the RC absorption coefficient at a wavelength of $830 \mathrm{~nm}$.
However, Positron annihilation measurements have now been used to characterize As-vacancies. According to recent, opticallyinduced positron annihilation measurements, an As-vacancy type defect ionises to its negative charge state under illumination of photons with energies greater than $1.42 \mathrm{eV}$ and this can only be observed at sample temperatures in the range of 20-150 K, consistent with RC observations [29].

Indeed, there is excellent agreement between concentrations of the negative As-vacancy produced by photoexcitation near $\mathrm{E}_{\mathrm{g}}$ and $\mathrm{RC}$ absorption coefficient (Figure 7) [29]. It follows that RC absorption is probably the ionisation of the Asvacancy to its negatively charged state.

\section{APPENDIX: OTHER DEFECTS}

EL2 and RC defects are spatially non-uniform resulting in inhomogeneities in substrate parameters. These non-uniformities are a result of the presence of dislocations introduced on growth and these affect other defects in bulk SI GaAs.

There are three other defect types that occur in this material and are of possible significance to devices; native point defects other than EL2 and RC, dislocations and second phases.

\subsection{Point Defects}

A multitude of levels, mostly donors whose ionisation energies are less than EL2, have been reported using deep level measurements such as DLTS [30]. The authors are not aware of whether any of these results in modifications to device performance. Only two such levels have come under detailed scrutiny, ELO which has an ionisation level close to EL2 and can cause confusion in the interpretation of DLTS data [31], and EL3, which has interesting properties and which may involve an oxygen atom [32].

\subsection{Electrical effects of Dislocations}

Much work in silicon has demonstrated that dislocations cause a significant degradation in device performance and it is also been proven that dislocations cause the rapid catastrophic failure from lasers fabricated on GaAs. In the latter case, the rapid degradation is thought to result from an interaction between the dislocations and the very strong injection of carriers. As a result, dislocations are found to climb and when their "volume" reaches that of the active area of the laser, the device fails [33]. On the other hand, SI GaAs is used mostly for majority carrier devies under circumstances where injection is 

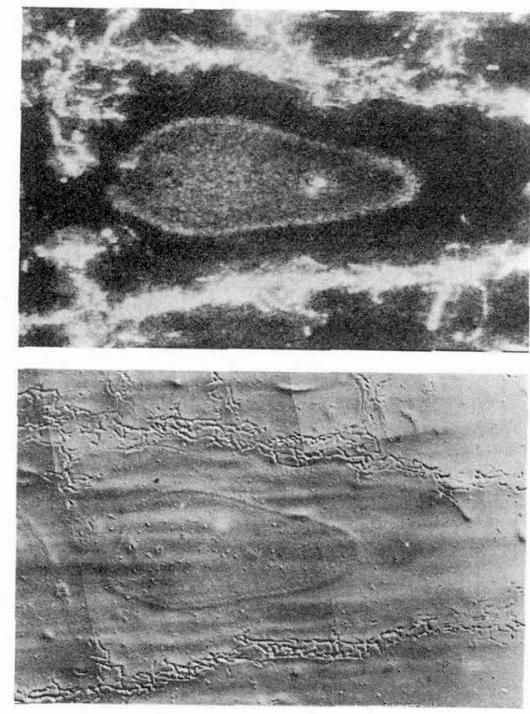

Figure 8. The upper image from light scattering tomography shows the distribution of arsenic precipitates. The lower image is an optical micrograph of the same section of sample after it has been etched to reveal dislocations. relatively limited. Early reports that dislocations affect the threshold voltage of MESFETs were shown to be incorrect as it was the atmospheres of point defects around the dislocations, rather than the dislocations themselves, that were causing the device degradation. A previous view that dislocations were important in reducing the minority carrier lifetime have also been shown to be incorrect. It can be deduced, with the information available at present, that dislocations are not important of themselves in device properties.

\subsection{Second Phases}

SI GaAs contains microprecipitates spatially associated with dislocations and which have been shown by several groups to consist of hexagonal arsenic [34]. Such precipitates can be revealed by TEM, by light scattering tomography or simply by etching the surface, see figure 8 [35]. Recently, it has been shown that such precipitates can affect MESFET performance and many researchers have been using specialised heat treatments of both the ingots and wafers in order to ameloriate their effects [36]. The efficacy of these heat treatments in the production of MESFETs and other devices with more uniform properties has been demonstrated, but this material is still rather experimental and most commercial GaAs retains the precipitates. Because of the scarcity of experimental data on devices fabricated from this new material, there remains uncertainty as to whether precipitates are as important as these groups suggest and whether it is therefore necessary to perform these rather complicated heat treatments. There have also been reports that texture of epitaxial layers on SI GaAs results from growth changes at these precipitates [37]. Once again, it would be expected that a reduction in precipitate size or number would be advantageous.

There has been a single report of microvoids within dislocation cells [38], the importance of which is quite uncertain but would apparently be amenable to positron annihilation investigation if this were thought necessary.

\section{CONCLUSIONS}

Distributions of two important point defects in SI GaAs are controlled by dislocations. One of them is the $\mathrm{As}_{\mathrm{Ga}}$ (EL2) defect whilst the other is the $\mathrm{V}_{\mathrm{As}}$ defect. Positron annihilation techniques have been very useful in the identification of both of these.

\section{ACKNOWLEDGEMENT}

The authors are grateful to Miss J Gilmore for the careful preparation of this manuscript. 


\section{REFERENCES}

[1] Sze S M, (Physics of Semiconductor Devices, Wiley, New York, 2nd Edition, (1981)

[2] Jordan A S, Caruso R and von Neida A R, Bell Syst Tech J, 59, (1980) p.593

[3] Breivik L, Brozel M R, Stirland D J and Tüzemen S, Semicond Sci \& Tech 7, (1992) p.269

[4] Doering P J, Friedenreich B, Tobin R J, Pearah P J, Tower J P and Ware R M (Proc 6th Int Conf Semi Insulating Mats, Toronto, 1990, Adam Hilger, Bristol, (1990)) p.173

[5] Martin G M, Farges J P, Jacob G and Hallais J Appl Phys, 51, (1980) p.2840

[6] See, for example, Pooni J S and Brozel M R, (Inst Phys Conf Ser, 145, 1993) p.211

[7] Martin G M, Appl Phys Lett 39, (1981) p.747

[8] Brozel M R, Grant I, Ware R M and Stirland D J, Appl. Phys. Lett. 42(7), (1993), p.610

[9] Brozel M R, Grant I, Ware R M, Stirland D J and Skolnick M S, J Appl Phys, 56(4), (1984) p.1109

[10] Rumsby D, Grant I, Brozel M R, Foulkes E J and Ware R M, (Semi Insulating III-V Mats, KahNee-Ta, 1984, Shiva publishing, Nantwich, UK, 1984) p.160

[11] For a recent review see Baraff G A (Proc 7th Int Conf Semi Insulating Mats, Ixtapa, Mexico, Eds. Miner CJ, Ford W and Weber E R, IOP Publishing, 1993) p.11

[12] Chadi D J and Chang K J, Phys Rev Lett, 60, (1988) p.2187

[13] Krause R, Saarinen K, Hautojärvi P, Polity A, Gartner G and Corbel C, Phys Rev Lett, 65(2), (1990) p.3329

[14] Le Berre C, Corbel C, Brozel M R B, Tüzemen S, Kuisma S, Saarinen K and Hautojärvi, submitted $J$ Phys (C), (1994)

[15] Carver G E, Semicond. Sci. \& Tech. 7, (1992) p.A54

[16] Skolnick M S, Reed L J and Pitt A D, Appl. Phys. Lett. 44 (1984), p.447.

[17] Miner C, Harrișon A and Clayton R, (Proc 7th Int Conf Semi Insulating Mats, Ixtapa, Mexico, Eds Miner C J, Ford W and Weber E R, IOP Publishing, 1993) p189

[18] Tüzemen S and Brozel M R, (Proc 7th Int Conf Semi Insulating Mats, Ixtapa, Mexico, Eds Miner C J, Ford W and Weber E R, IOP Publishing, 1993) p.223

[19] Jimenez J, Alvarez A, Bonnafe J and Murin L I, Phys. Rev.B 39(18), (1989) p.13310

[20] Breivik L, Brozel M R, Mohades-Kassai A and Langer J M, (Proc. 6th Conf. on Semi-Ins. III-V Materials, Toronto 1990, Eds. A G Milnes and C J Miner, Adam Hilger, Bristol, 1990) p.257

[21] Tüzemen S and Brozel M R, Appl. Surface Sci. 50, (1991) p.395 
[22] Stirland D J, Gall P, Brozel M R, Breivik L, Williams G M, Cullis A G and Fillard J P, (Gallium Arsenide and Related Comp. 1990, Ins. Phys. Conf. Ser. 112, Ed. K E Singer), p.55, 1991.

[23] Tüzemen S, Breivik L and Brozel M R, (Semicond. Sci. \& Technol. 7, 1992), p.A36

[24] Tüzemen S and Brozel M R, (Materials Sci. \& Eng. B14, p.47, 1992)

[25] Tüzemen S, Brozel M R and Breivik L, J. (Electronic Mat. 21(3), 389, 1992)

[26] Brozel M R and Tüzemen S (Proc 7th Int Conf Semi Insulating Mats, Ixtapa, Mexico, Eds Miner C J, Ford W and Weber E R, IOP Publishing, 1993) p.187

[27] Puska M G, Jepsen O, Gunnarson O and Neiminen R M, Phys. Rev., B34(4), (1986), p.2695

[28] Lin-Chung P J and Reinecke T L, Phys. Rev. B27(2), (1983) p.1101

[29] Le Berre C, Corbel C, Mih R, Brozel M R, Tüzemen S, Kuisma S, Saarinen K, Hautojärvi P and Fornari R, submitted to Appl Phys Lett, (1994)

[30] See, for example, Brozel M R (Defect Densities in SI LEC GaAs in Properties of GaAs, 2nd edition, EMIS Datareview series no 2, 1990) p.309

[31] Okumura T and Hoshimo M (Proc Semi Insulating III-V Mats, Pub. Ohmsha, 1986) p.409

[32] Alt H Ch, Yahata A, Okushi $\mathrm{H}$ and Ishida K, (Proc Semi Insulating III-V Mats, Pub. Ohmsha, 1986) p.415

[33] Petroff P and Hartman R L, Appl Phys Lett, 23(8) p.469

[34] Cullis A G, Augustus P D and Stirland D J, J Appl Phys, 51, (1980) p.2556

[35] Stirland D J, Gall P, Brozel M R, Breivik L, Williams G M, Cullis A G and Fillard J P, (Gallium Arsenide and Related Comp. 1990, Ins. Phys. Conf. Ser. 112, Ed. K E Singer), p.55, 1991.

[36] Oda O, Yamamoto H, Seiwa M, Kano G, Inoue T, Mori M, Shimakura H and Oyake M (Semicond Sci Tech, Proc DRIP IV, 1992) p.A215

[37] Smith R, Private Communication, 1993

[38] Stirland D J, (Proc Micros Semiconducts, Inst Phys Conf Ser No 117, IOP Pub, 1991) p.327 